\title{
AVALIAÇÃO DA DENSIFICAÇÃO DE UMA MISTURA DE ENROCAMENTOS PARA DIFERENTES TEORES DE FINOS
}

\section{DENSIFICATION EVALUATION OF A MIXTURE OF RIPRAP FOR DIFFERENT FINE CONTENTS}

\author{
Murilo ESPÍNDOLA ${ }^{1}$; Marciano MACCARINI ${ }^{2}$ \\ (1) Laboratório de Geotecnia Aplicada, Departamento do Geociências, Universidade Federal de Santa Catarina, Florianópolis, SC. \\ Email: murilo.espindola@ufsc.br \\ (2) Laboratório de Mecânica dos Solos, Departamento de Engenharia Civil, Universidade Federal de Santa Catarina, Florianópolis, SC.
} Email: maccarini.m@ufsc.br

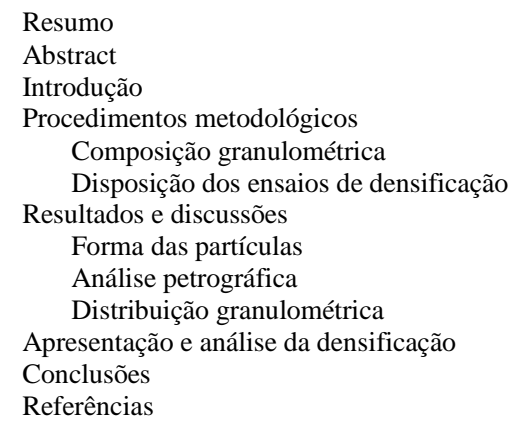

RESUMO - Com a aprovação da Lei $\mathrm{N}^{\circ} 12.334$ (Lei de segurança de barragens), pesquisas com tal finalidade passaram a ter mais relevância, pois o aumento de confiabilidade na avaliação de barragens de enrocamento e o ganho de segurança beneficia o setor elétrico nacional. Para barragens existentes, o melhor conhecimento dos enrocamentos permite determinar de forma mais precisa valores de referência para níveis de atenção e alerta, possibilitando melhor previsibilidade de seu comportamento, e reduzindo-se riscos de prejuízos sociais e econômicos. O objetivo geral desta pesquisa consistiu em avaliar a densificação dos enrocamentos da Usina Hidrelétrica Machadinho, frente à influência da adição de finos e água, obtidos em equipamentos para ensaios de grande escala. Foram executados ensaios de caracterização e densificação, em equipamento com amostragem de $660 \mathrm{~mm}$ de diâmetro e $700 \mathrm{~mm}$ de altura, placa vibratória com controle de frequência, e diâmetros máximos de partículas introduzidas nos protótipos granulométricos de laboratório de $130 \mathrm{~mm}$. Foi verificado que a densificação de enrocamentos com teores elevados de finos é dificultada por tensões capilares, quando adiciona-se água ao material. Identificou-se ainda que, a introdução de litologias menos nobres no corpo de aterros de barragens deve estar associada a curvas granulométricas bem graduadas, de forma que sejam minimizados os efeitos de quebra de partículas.

Palavras-chave: enrocamento, densificação, barragem.

\begin{abstract}
With the approval of Law No. 12.334 (Law on dam safety), research to this end has become more relevant, since the increase of reliability in the evaluation of riprap dams and the safety gain benefits the national electric sector. For existing dams, better knowledge of riprap allows to more accurately determine reference values for levels of attention and alertness, allowing better predictability of their behavior, and reducing risks of social and economic losses. The general objective of this research was to evaluate the densification of the rockfills of the Machadinho Hydroelectric Power Plant, in light of the influence of the addition of fines and water, obtained in equipment for large scale trials. Characterization and densification tests were carried out in equipment with $660 \mathrm{~mm}$ diameter and $700 \mathrm{~mm}$ high sampling, vibration plate with frequency control, and maximum particle diameters introduced in $130 \mathrm{~mm}$ laboratory granulometric prototypes. It has been found that the densification of ripraps with high fines contents is hampered by capillary stresses when water is added to the material. It was also identified that the introduction of less noble lithologies in the body of dam embankments should be associated with well-graded grain sizes, so that the effects of particle breakage are minimized.
\end{abstract}

Keywords: riprap, densification, dam.

\section{INTRODUÇÃO}

O desenvolvimento da geotecnia, ao que se encontra atualmente, se deu em dois aspectos principais. De um lado, materiais puramente arenosos, com tendências drenantes e atrito predominante entre partículas, de outro, maciços puramente argilosos, com inclinações pouco drenantes e ligações verdadeiras entre grãos. Em ambos os casos, a quebra de partículas não viria a ser uma variável predominante. Não obstante, a aplicação da teoria da mecânica dos solos moderna em enrocamentos de barragens necessitou de avanços tecnológicos, tendo em vista sobretudo os estados de tensões aos quais estas partículas são submetidas, podendo ocorrer a quebra de grãos.

Portanto, a aplicação dos estudos desenvolvidos pós Terzaghi em materiais de 
enrocamentos tem sido chamada de Mecânica de Enrocamentos.

É uma tendência na prática de construção de barragens de enrocamentos a utilização de teores cada vez mais elevados de finos e rochas de qualidade mais baixa. Igualmente é comum a adição de água durante a densificação, a qual tem como objetivo principal minimizar deformações acentuadas durante o enchimento do reservatório.

Pacheco (2005), Hummes (2007) e Meirelles (2008) realizaram experimentos mecânicos de grande escala no Laboratório de Mecânica dos Solos da Universidade Federal de Santa Catarina (LMS/UFSC), tendo observado que a combinação do aumento de finos com a adição de água poderia dificultar a densificação do enrocamento.

Por outro lado, após a construção, elevados teores de finos e sua saturação podem causar redução da resistência do enrocamento e colapso da estrutura, como consequência, diminuição da segurança do corpo da barragem.

Portanto, frente as dúvidas alçadas, sugeriram que as novas pesquisas determinassem até que ponto o aumento da porcentagem de finos não prejudica $o$ comportamento mecânico dos enrocamentos, e a combinação de finos e água não dificulta sua densificação. Maccarini et al. (2014) citam que não há um consenso claro no meio técnico quanto à definição qualitativa e quantitativa de finos em enrocamentos destinados a construção de barragens de grande porte.

É necessário estabelecer relação entre o teor de finos e comportamento mecânico, indicando a inclusão máxima a partir da qual esses não prejudicam a segurança de barragens.

As primeiras barragens de enrocamento foram construídas nos Estados Unidos da América, México e alguns países da Europa, buscou-se explorar o potencial hídrico destes países. Consequentemente, os estudos pioneiros em comportamento mecânico e ensaios de grande escala em enrocamentos são decorrentes deste processo exploratório, no México e EUA, principalmente.

Em um segundo momento, com a redução da construção de barragens de enrocamento nos países citados, fruto da saturação do potencial hidrelétrico, reduziram-se também as pesquisas neste tema. Não obstante, países como Brasil,
China e outros quantos da África ainda possuem potencial a ser explorado. Cruz et al. (2014) citam que existem cerca de 300 barragens de enrocamento com face de concreto em construção em todo o mundo, sendo aproximadamente 180 na China.

A maior barragem de enrocamento com face de concreto desse País possui 233 metros de altura, em Shuibuya, tendo superado a barragem de Campos Novos (202m), no Brasil.

Araei et al. (2010) descrevem que a realização de ensaios e a correta modelagem de enrocamentos são requisitos mínimos para análises reais e elaboração de projetos econômicos de barragens de enrocamento.

Estes materiais possuem partículas de tamanhos consideráveis, e requerem equipamentos de dimensões atípicas.

Cruz et al. (2014) enfatizam que o ressurgimento de equipamentos edométricos e triaxiais de grande escala tem propiciado dados numéricos para cálculos de elementos finitos e avaliação do desempenho de barragens. Divino (2010) descreve que a deformabilidade é um dos parâmetros mais importantes na análise do comportamento mecânico de enrocamentos, e que está diretamente relacionada a resistência dos materiais.

No caso de enrocamentos, devem ser considerados intervenientes como o arranjo de partículas e a composição mineralógica. Lambe \& Whitman (1969) selecionaram dois aspectos principais para justificar a compressibidade de solos granulares: a quebra de partículas e o rolamento de grãos. Não obstante, destacam ainda que raramente estes mecanismos são independentes.

A deformação é uma propriedade que os enrocamentos possuem de alterar sua forma, frente às solicitações de tensões decorrentes de obras de engenharia. As proporções das deformações dependem das características do material, tais como composição, índice de vazios, estado de tensões, entre outras. Terzaghi (1960) descreve que o enrocamento ideal é aquele composto por material mais bem graduado, uma vez que a resistência ao cisalhamento nestas condições seria mobilizada logo para pequenas deformações. Fato oposto, para materiais mal graduados seriam necessárias grandes deformações para mobilização da resistência ao cisalhamento. 
Lambe \& Whitman (1969) explicam que se as partículas fossem rígidas e não deslizassem umas em relação as outras, as deformações seriam mínimas. Os movimentos entre partículas são responsáveis pelas grandes deformações, todavia, se as mesmas não deformassem e distorcessem, não haveria movimentos relativos (Figura 1).

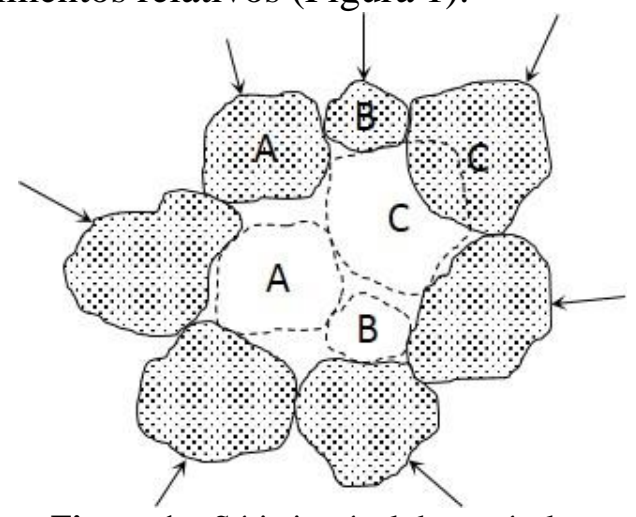

Figura 1 - Série instável de partículas.

Marsal \& Rosa (1976) publicaram os primeiros resultados laboratoriais de misturas de enrocamentos com areias, siltes e argilas. Os materiais eram oriundos da fragmentação de rochas basálticas densas. A Figura 2 apresenta os dados de densificação dos materiais citados, por meio de procedimento dinâmico. Divino (2010), ao analisar tais dados, cita que os procedimentos de vibração nas misturas de composições arenosas são eficientes para um percentual de $45 \%$, tendo atingido índice de vazios mínimo igual à 0.27 . É possível observar que os demais materiais apresentam valores da ordem de 0.50 e 0.55 .

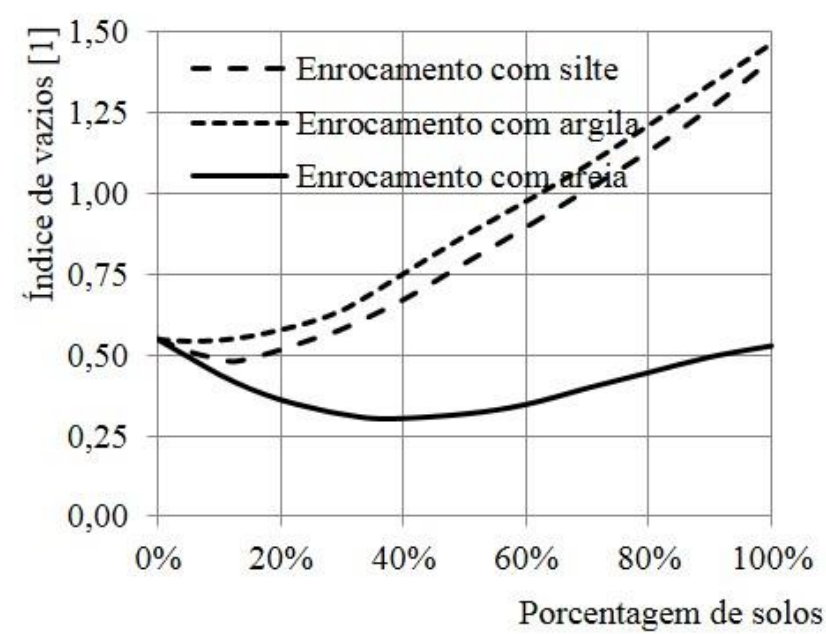

Figura 2 - Dados de densificação das misturas de Marsal \& Rosa (1976).

Yamaguchi (2009) compactou enrocamentos de dacito e arenito em molde metálico com $300 \mathrm{~mm}$ de diâmetro e $600 \mathrm{~mm}$ de altura, com uma placa vibratória de $37.9 \mathrm{~kg}$. O autor tomou o cuidado de avaliar a densificação dos materiais em função do tempo de vibração, tendo obtido os resultados expostos na Figura 3.

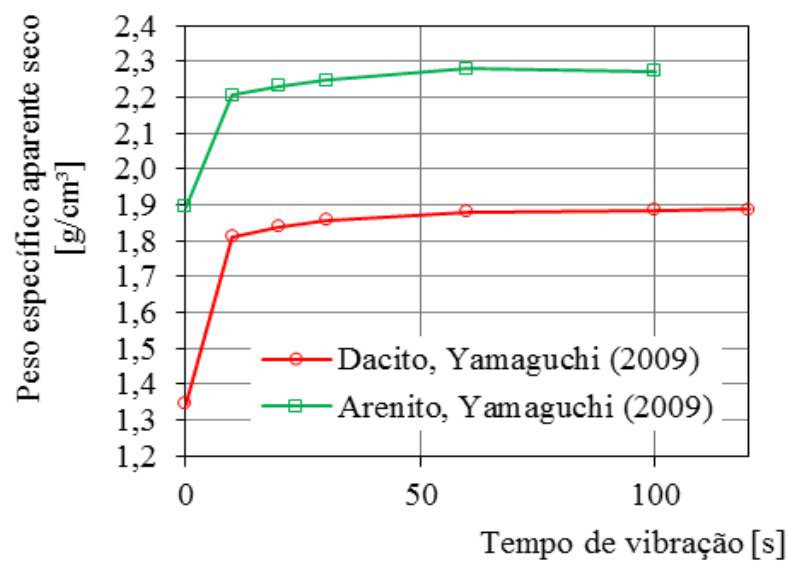

Figura 3 - Densificação versus tempo de vibração por Yamaguchi (2009).

É importante observar que as deformações basicamente estabilizam aos 60 segundos, não se observando ganhos significativos para tempos posteriores. É possível, inclusive, que a continuidade do procedimento de vibração a partir dos 60 segundos prejudique o material, tendo em vista que com a aproximação das partículas, aumenta-se a possibilidade de quebras, ao passo que o ganho de resistência por densificação é pouco significativo.

A Usina Hidrelétrica Machadinho (1.140MW) está situada no Rio Pelotas, mil e duzentos metros à jusante da foz do Rio Ihandava, fazendo divisa nos municípios de Piratuba/SC e Maximiliano de Almeida/RS.

A barragem possui uma altura total de 126 metros, com corpo composto de enrocamento vulcânico, e mistura de $70 \%$ de riodacito com $30 \%$ de brecha basáltica, material menos nobre.

O maciço foi compactado utilizando 100litros de água para cada $1 \mathrm{~m}^{3}$ de enrocamento compactado. Esta barragem difere de outras de enrocamento no Brasil, por possuir uma quantidade de finos mais significativa.

Tendo em vista as características diferenciadas que envolveram a construção da UHE Machadinho, e a necessidade de se avaliar o comportamento destes materiais em equipamentos de escalas mais representativas, foi proposto para esta pesquisa analisar os dados de densificação dinâmica com a adição de diferentes porcentagens de finos, com e sem a presença de água no procedimento. 


\section{PROCEDIMENTOS METODOLÓGICOS}

O Laboratório de Mecânica dos Solos da Universidade Federal de Santa Catarina dispõe de estrutura para realizar ensaios de grandes dimensões, os equipamentos foram doados após a construção da hidroelétrica de Itaipu, tendo sido reformulados com o aporte financeiro da Tractebel Energia S.A., e expressiva colaboração do engenheiro Rodrigo André Hummes, conforme descrevem Hummes e Maccarini (2009).

Os ensaios convencionais em enrocamentos disponíveis na literatura, predominantemente são realizados em escala aproximada de 1:20. Ou seja, um material de 1000 milímetros de diâmetro é reduzido à 60 milímetros em uma curva protótipo. A pesquisa realizada ampliou a confiança dos parâmetros obtidos, uma vez que aumentou a escala para aproximados 1:7, com partículas de até 135 milímetros de diâmetro. Houve, assim, um ganho de até 2.5 vezes na escala e na precisão dos estudos.

Veiga Pinto (1983) disserta acerca da representatividade de ensaios de laboratório, concluindo que é essencial que haja semelhanças na granulometria, no estado de compacidade e na forma das partículas.

Foi utilizado como base o enrocamento da Usina Hidrelétrica Machadinho, da Tractebel Energia S.A., que é composto por $70 \%$ de riodacito e $30 \%$ de brecha basáltica. Avaliou-se a influência da adição de materiais finos (menores que 0.075 milímetros de diâmetro) na densificação. Ao enrocamento foram introduzidos $5 \%, 10 \%, 15 \%$, e $20 \%$ destas partículas, tendo sido verificado ainda o comportamento frente a adição de água.

O volume de água adicionado foi de 5.6 litros por camada $(107.8 \mathrm{~kg}$, seco), resultando $\mathrm{em}$ teor de umidade (w\%) de $5.2 \%$. Considerando partículas com peso específico de sólidos médio de $26.08 \mathrm{kN} / \mathrm{m}^{3}$ (Pacheco, 2005), o volume de água adicionada em relação ao volume de sólidos foi de $13.8 \%$.

\section{Composição granulométrica}

O processo de preparação de materiais para ensaios consistiu na britagem das partículas maiores, utilizando peneiras com aberturas de malhas entre $0.075 \mathrm{~mm}$ e $38.1 \mathrm{~mm}$, armazenamento das frações retidas e passantes em baias e mistura das diversas frações em proporções equivalentes às de campo. Em um primeiro momento, as litologias foram trabalhadas isoladamente, e após a obtenção dos diferentes tamanhos de partículas foram realizados ensaios com misturas dos dois materiais nas proporções utilizadas na construção da UHE Machadinho. O processo de britagem permitiu compor uma curva granulométrica protótipo, e empregá-la nos ensaios de densificação.

O britador de mandíbulas implantado para a pesquisa possui regulagem que permitiu obtenção de partículas grossas com dimensões menores que $76 \mathrm{~mm}$, até materiais entre as peneiras $9.6 \mathrm{~mm}$ e $0.60 \mathrm{~mm}$, em que foram necessários de 3 a 5 ciclos de passagem. Partículas com diâmetro médio maior que 200mm não puderam ser encaminhadas para o britador, e nestes casos procedeu-se com a fragmentação manual dos grãos.

Verificou-se que o britador não permitiu obtenção de quantidades significativas de materiais passantes na peneira $0.075 \mathrm{~mm}$. A solução do problema exigiu a utilização de moinho de rodas. A maior parte das frações menores que $0.60 \mathrm{~mm}$ foram obtidas a partir de moagem de materiais passantes na peneira $4.8 \mathrm{~mm}$. O moinho de rodas utilizado nesta pesquisa é composto por cilindro com diâmetro de $80 \mathrm{~cm}$ e duas rodas de aço maciças com diâmetro de $30 \mathrm{~cm}$, acionadas por eixo acoplado a motor elétrico.

A Figura 4 apresenta a mesma amostra de riodacito antes e após moagem por 12 minutos, respectivamente. Observa-se que o volume de material após a moagem foi maior, consequência de seu maior índice de vazios, relacionado com o inverso das dimensões das partículas.

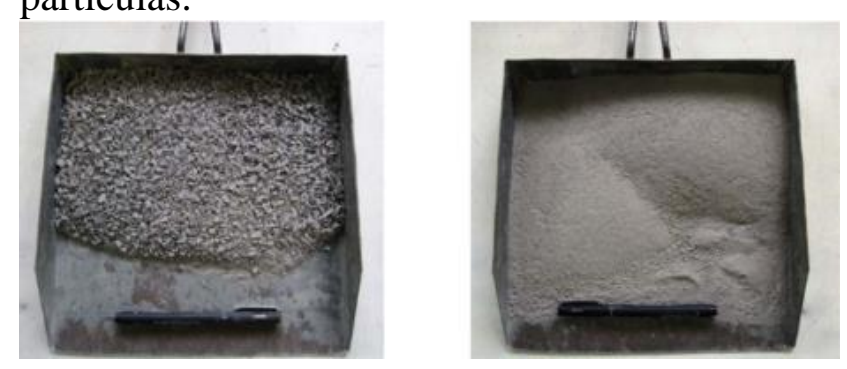

Figura 4 - Riodacito antes a após a moagem.

Uma vez atingida, para todas as frações, a massa mínima necessária para realização dos ensaios de densificação, estas foram misturadas 
em proporções previamente determinadas para atingir curva granulométrica paralela à de campo (Figura 5).

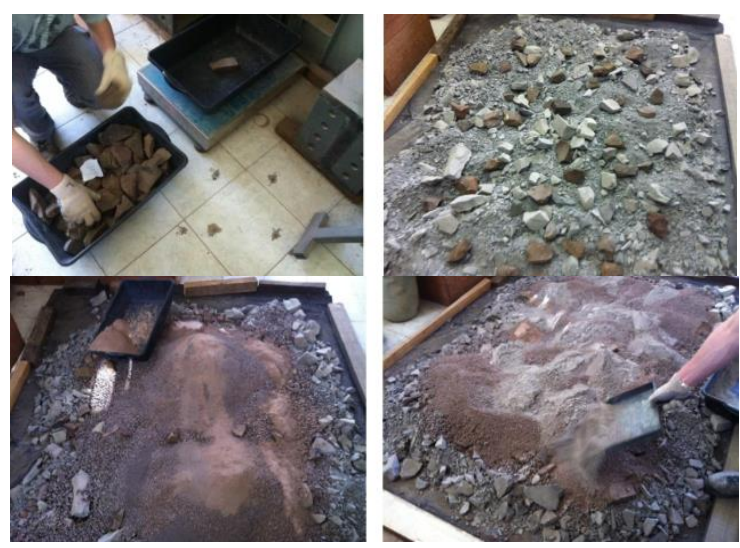

Figura 5 - Pesagem e adição de partículas à mistura.

Adotou-se para todas as frações, proporção de $30 \%$ de brecha basáltica e $70 \%$ de riodacito, conforme especificação seguida durante a construção da UHE Machadinho. A massa total obtida, após a composição granulométrica foi de $482 \mathrm{~kg}$.

\section{Disposição dos ensaios de densificação}

Os ensaios de densificação foram realizados em molde de aço com diâmetro interno de $660 \mathrm{~mm}$ e altura de $700 \mathrm{~mm}$. Verificou-se que a frequência de vibração da placa vibratória utilizada $(88 \mathrm{~Hz})$ estava acima do valor geralmente adotado para enrocamentos (20 a $40 \mathrm{~Hz})$.

Com objetivo de simular de forma mais fiel a situação de campo, realizada por rolos vibratórios, foi adquirido um painel de acionamento variável capaz de controlar a frequência de vibração da placa.

Durante a colocação e espalhamento do enrocamento no interior do molde, foram adotados critérios tais como o posicionamento manual das partículas maiores que $76 \mathrm{~mm}$, com objetivo de não as deixar em contato direto com o fundo e paredes do molde, e umas com as outras. Isso poderia resultar em grandes espaços vazios, não representativos do que ocorre em campo, posicionaram-se as partículas maiores e, após, das menores.

A Figura 6 apresenta o molde, a base de aço sobre a qual este foi fixado, e a placa vibratória posicionada sobre o mesmo.
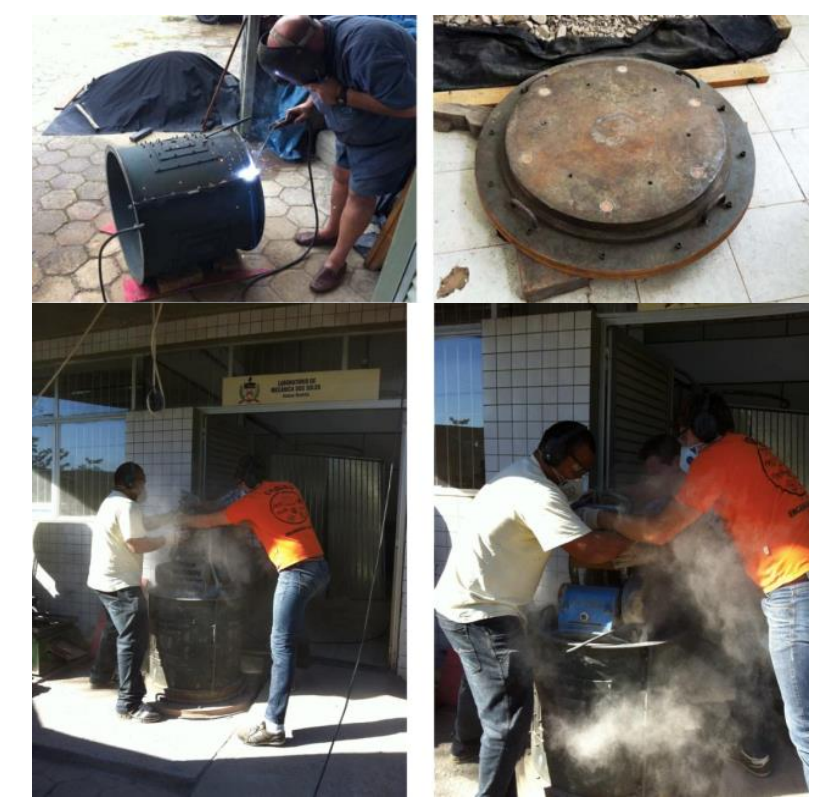

Figura 6 - Molde metálico e placa vibratória.

Dessa forma, evitou-se que a placa vibratória ficasse apoiada sobre poucas partículas grandes situadas no topo da camada, prejudicando a densificação, e possibilitando acréscimo de quebra de partículas.

Conforme descreve Breitenbach (1993), adotou-se frequência de vibração de $45 \mathrm{~Hz}$. O tempo de vibração foi de 60 s por camada, durante $o$ qual a placa foi continuamente rotacionada.

$\mathrm{Na}$ Figura 06 observa-se a grande quantidade de finos em aspersão, visto que se refere a uma condição seca com $15 \%$ de passantes na $0.075 \mathrm{~mm}$.

\section{RESULTADOS E DISCUSSÕES}

Os resultados apresentados neste item são decorrentes de projetos de pesquisa financiados pela Tractebel Energia S.A., em parceria com a Universidade Federal de Santa Catarina. São comparados com resultados de outros autores. Pacheco (2005) ao caracterizar os materiais da UHE Machadinho obteve valores de absorção iguais à $6.67 \%$ para a brecha basáltica e $2.21 \%$ para o riodacito.
A perda de massa por abrasão Los Angeles foi de $23.64 \%$ na brecha e $11.89 \%$ no riodacito. Os valores de peso específico dos sólidos foram de $25.1 \mathrm{kN} / \mathrm{m}^{3}$ para a brecha e $26.6 \mathrm{kn} / \mathrm{m}^{3}$ para o riodacito.

\section{Forma das partículas}

Foram verificadas partículas de formas prismáticas, com bordas afiadas à arredondadas para a Brecha, e prismáticas e planas para o 
Riodacito. Caracterizou-se 1400 partículas, conforme Marsal (1973), constituídas entre as faixas granulométricas de $19.1 \mathrm{~mm}$ e $135 \mathrm{~mm}$. Meirelles (2008), em pesquisa realizada anteriormente, determinou também os coeficientes de forma dos enrocamentos da UHE Machadinho. A Figura 7 demonstra $\mathrm{O}$ enquadramento das partículas dos enrocamentos estudados neste trabalho, no qual se verifica uma tendência à esfericidade maior da Brecha Basáltica, e vertentes lamelares para o Riodacito. Evidencia-se ainda formatos mais prismáticos para partículas maiores, com ocorrência de pontos na região de basalto denso, bem graduado de partículas de elevada resistência.

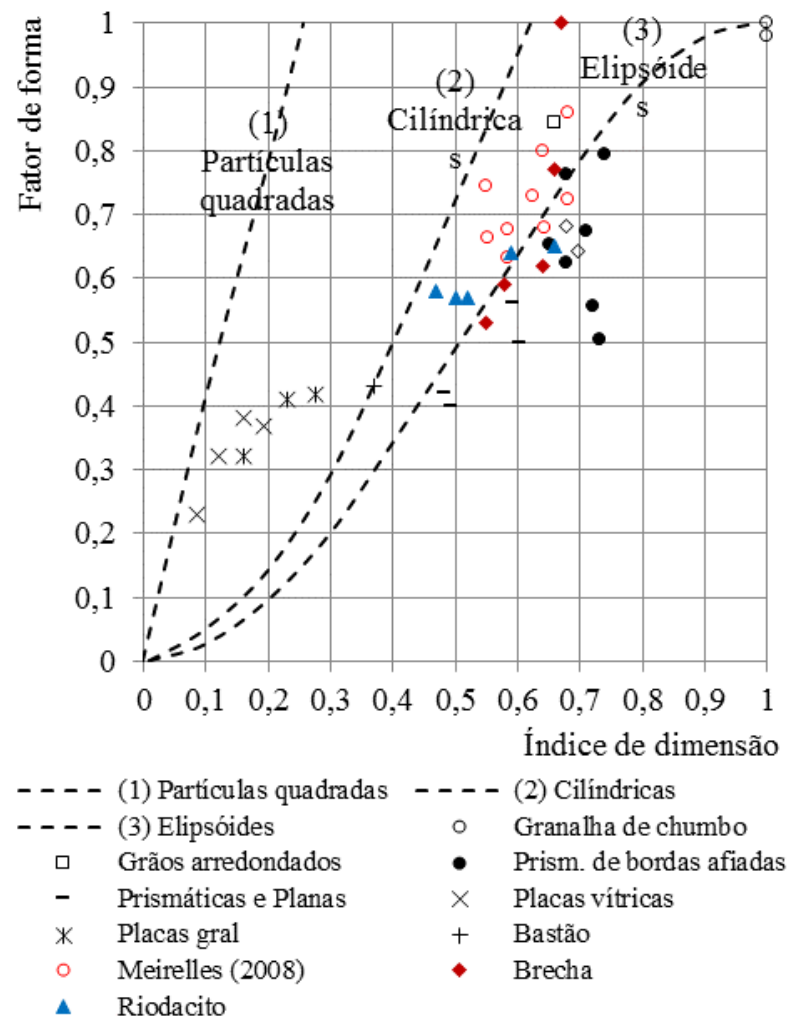

Figura 7 - Coeficiente de forma dos grãos segundo Marsal (1973).

Fato importante a ser exposto no presente trabalho foi o número de partículas que constituiu uma mesma massa em determinada faixa granulométrica, pois à exemplo das partículas menores que $135 \mathrm{~mm}$ e retidas na peneira $76 \mathrm{~mm}$, em uma massa de $84.000 \mathrm{~g}$, foram contabilizadas 43 partículas de Brecha Basáltica, e 82 partículas de Riodacito. Ou seja, confirmando a tendência de formas mais planas desta última. Ainda que a forma das partículas tenha sido avaliada separadamente para cada litologia, o ensaio de densificação foi realizado respeitando-se a proporção utilizada na UHE Machadinho.

\section{Análise petrográfica}

As litologias que contemplaram esta pesquisa constam no mapa geológico de detalhes como riodacito e brecha basáltica, tendo sido assim também classificadas em análise macro. Como o foco deste trabalho consistiu na análise da densificação, foi mantida tal nomenclatura, e foi proposta ainda uma microanálise por petrografia, para as duas litologias.

Com base na análise petrográfica em microscópio óptico (Figura 8), a rocha que compôs $70 \%$ da mistura dos enrocamentos da UHE Machadinho foi classificada como Dacito, tendo sido posto em dúvida a possibilidade de ser um basalto, o que foi descartado rapidamente por análise da macroestrutura de coloração clara. É importante citar que no sistema de classificação proposto pelo geólogo Streckeinsen (1967), não constou a classificação "riodacito", trata-se, portanto, de uma nomenclatura de classificação geoquímica, face a presença de fenocristais.

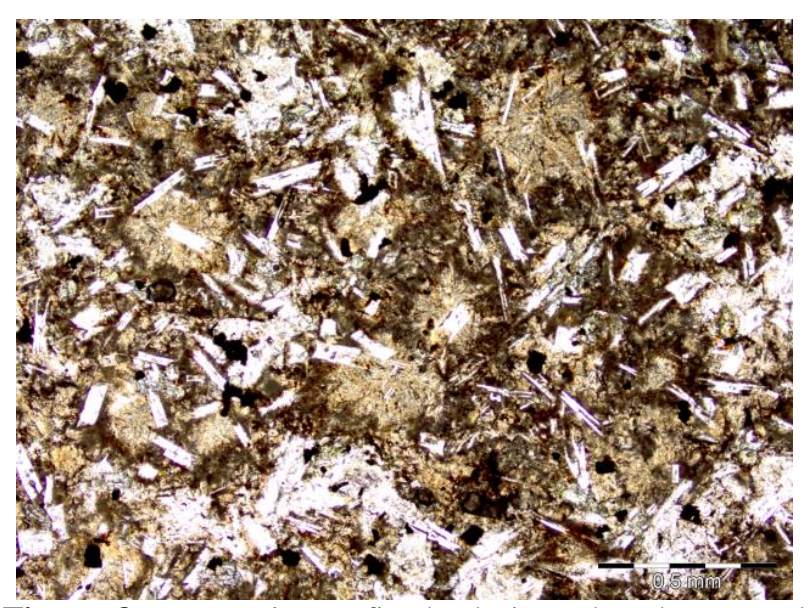

Figura 8 - Fotomicrografia de dacito sob a luz natural mostrando textura intersertal.

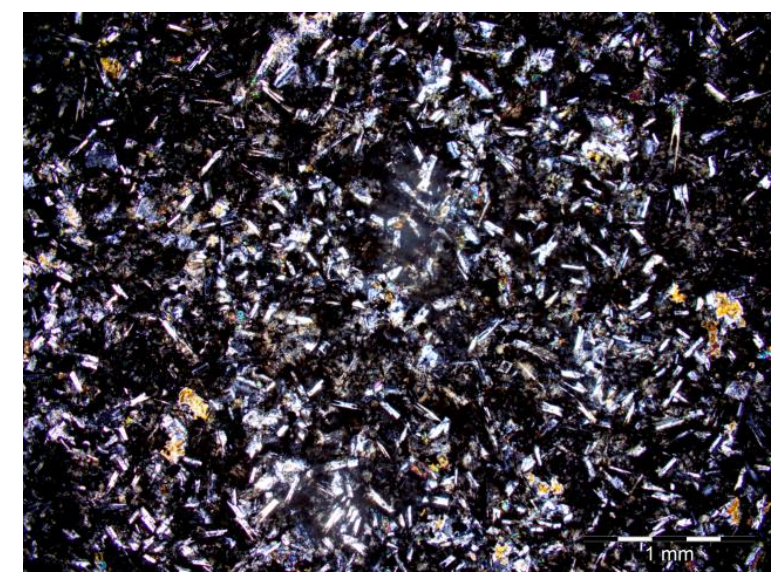

Figura 9 - Fotomicrografia de dacito sob polarizadores cruzados.

É possível observar que a rocha possui estrutura maciça com textura hipocristalina 
(mais cristais que vidro), hipidiomórfica (o hábito não é amorfo e nem bem formado), equigranular fina. Sua trama cristalina é intersertal que é definida como cristais euédricos e subédricos com interstícios de material vítreo. É composta principalmente por vidro vulcânico, plagioclásio, augita, quartzo, em menor quantidade tem-se apatita, feldspato alcalino, opacos e hidróxido de ferro. Sob a ação de polarizadores cruzados, o vidro vulcânico adquire coloração escura, conforme Figura 9.

O Plagioclásio ocorre em ripas sem orientação preferencial e também com hábito esqueletal (Figura 10). É branco sob luz natural e maclas polissintéticas com nicóis cruzados. O vidro é intersticial, e alguns cristais de quartzo possuem extinção ondulante, com hábito anédrico e cor branca em luz natural.

A augita é anédrica, castanha sob luz natural e birrefringência de $2^{a}$ a $3^{a}$ ordem. $O$ feldspato alcalino ocorre em pequenas quantidades, às vezes com hábito tabular, é branco em luz natural e ao cruzar os nicóis tem cores de $1^{\text {a }}$ ordem.

Os opacos são escuros tanto em luz natural quanto em polarizadores cruzados e com hábito geralmente euédrico.

O hidróxido de ferro é castanho e comumente aparece nas bordas dos minerais opacos. A
Apatita é incolor e se dispõe com hábito acicular e prismático.

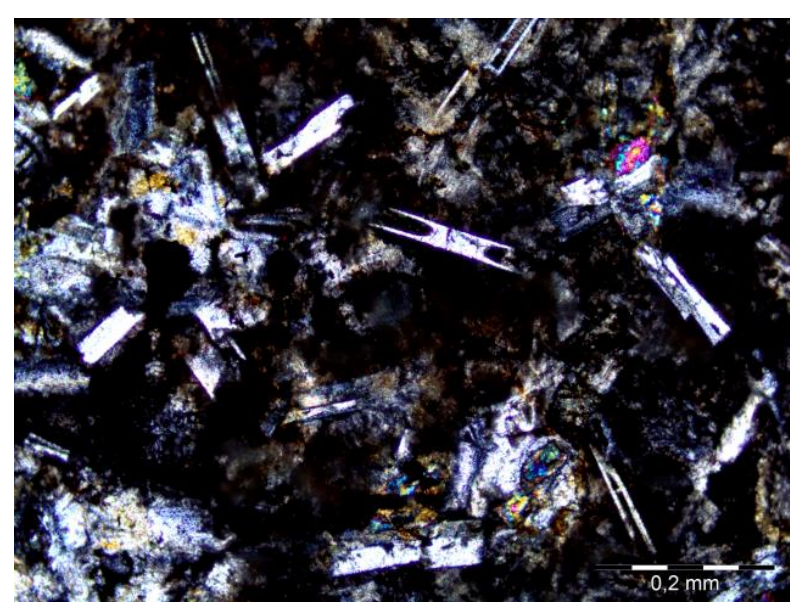

Figura 10 - Fotomicrografia de dacito mostrando em detalhe os cristais de plagioclásio esqueletal.

A presença de $41 \%$ de vidro vulcânico na composição mineralógica (Tabela 1) levanta a hipótese de que, ainda que os enrocamentos nobres da UHE Machadinho tenham elevada resistência à compressão simples $(\approx 100 \mathrm{MPa})$, as susceptibilidades ao intemperismo destes minerais da rocha abram espaço para possibilidade de queda de resistência das partículas sólidas.

Dos minerais apresentados, o plagioclásio, augita e o quartzo, são primários. A extinção ondulante observada neste mineral foi um registro de ocorrência de esforços tectônicos no maciço.

Tabela 01 - Composição mineralógica de litologia nobre.

\begin{tabular}{c|c|c}
\hline Mineral & Porcentagem & Dimensões \\
\hline Vidro vulcânico & $41 \%$ & - \\
\hline Plagioclásio & $28 \%$ & $\approx 0.20 \mathrm{~mm}$ \\
\hline Quartzo & $20 \%$ & $0.25 \mathrm{~mm}$ \\
\hline Augita & $5 \%$ & $\approx 0.15 \mathrm{~mm}$ \\
\hline Opacos & $4 \%$ & $\approx 0.10 \mathrm{~mm}$ \\
\hline Apatita & $<1 \%$ & $\approx 0.01 \mathrm{~mm}$ \\
\hline Hidróxido de ferro & $<1 \%$ & - \\
\hline K-Feldspato & $1 \%$ & $\approx 0.20 \mathrm{~mm}$ \\
\hline
\end{tabular}

Chmyz et al. (2011) estudaram os derrames da Formação Serra Geral, citando que durante o volumoso magmatismo, ainda que tenha ocorrido predominância de composição básica, cerca de $10 \%$ dos litotipos são de natureza intermediária a ácida.

Descreve que os materiais dos municípios de Palmas e General Carneiro, na divisa do Paraná com Santa Catarina, foram classificados por geoquímica (R1:R2) e petrografia (Streckeisen,
1967). Macroscopicamente, apresentam granulação muito fina, e são constituídas predominantemente por plagioclásio e vidro vulcânico. Estas rochas foram classificadas, segundo o diagrama R1:R2, como riolitos e riodacitos. Em referência aos riodacitos, a autora descreve que são constituídos por plagioclásio (25\%), quartzo (5\%), feldspato alcalino $(5 \%)$, minerais opacos $(15 \%)$ e augita (10\%), também em meio à matriz formada por 
vidro vulcânico (40\%). A partir de análises químicas, em base hidratada, a porcentagem de sílica dos riodacitos foi de $66.5 \%$, sendo ambos os litotipos de caráter ácido.

A rocha dita pobre que compôs $30 \%$ da mistura do corpo de aterro da UHE Machadinho possui estrutura vesicular, e não foi possível observar as amígdalas, com textura hipovítrea, o tamanho dos componentes variou de fino a denso, vitrofírica (Figura 11).

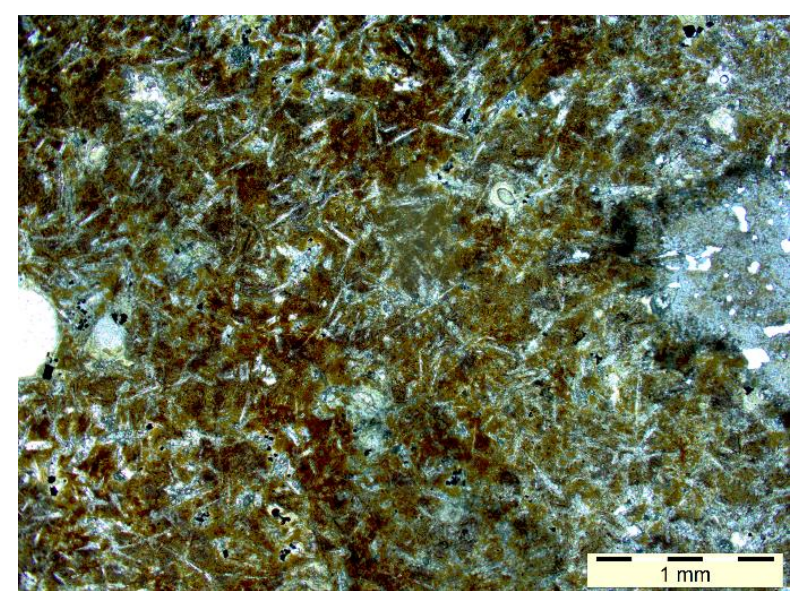

Figura 11 - Fotomicrografia de brecha basáltica, indicando vesículas em detalhe.

A forma predominante é hipidiomórfica (maioria dos cristais são subédricos) em relação a sua trama apresenta textura hialofítica (pequenas ripas de plagioclásio e piroxênio emersos em matriz vítrea), conforme Figura 12. Quanto ao seu índice de coloração a rocha é mesocrática, e constituída principalmente por vidro, plagioclásio e clinopiroxênio, subordinadamente por ortoclásio e óxidos.

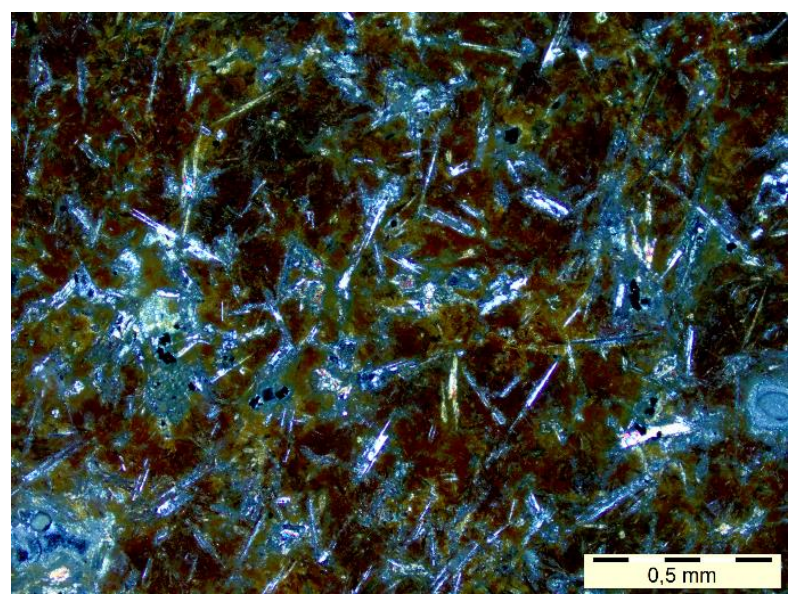

Figura 12 - Fotomicrografia de brecha basáltica em maior detalhe, mostrando ripas de plagioclásio com textura esqueletal.

Observa-se que o plagioclásio se dispõe em pequenas ripas alongadas, com formas em geral bem definidas e textura esqueletal. $\mathrm{O}$ clinopiroxênio é incolor sob luz natural, porém com cor de interferência mais alta ao cruzar os polarizadores e tem hábito tabular a prismático (Figura 13).

O ortoclásio tem hábito tabular e aparece esporadicamente em pequenos cristais. Os minerais opacos (geralmente óxidos de ferrotitânio) são escuros, com ou sem polarizador, com formas geralmente bem definidas e geralmente estão aglomerados. O vidro é castanho claro e perfaz a matriz da rocha.

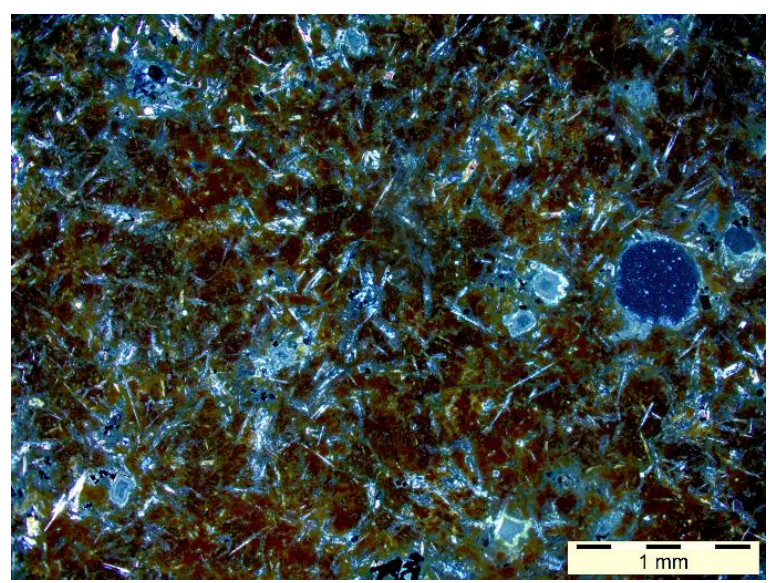

Figura 13 - Fotomicrografia de brecha basáltica, mostrando aspecto geral da rocha.

A Tabela 2 apresenta as porcentagens mineralógicas que compõem a litologia pobre da mistura.

\section{Distribuição granulométrica}

As frações granulométricas geradas foram misturadas em proporções adequadas à obtenção de material suficiente para a reprodução da curva granulométrica paralela a de campo, obedecendo um tamanho máximo de partículas. O tamanho máximo das partículas foi definido conforme relação de $1 / 5$ do diâmetro do corpo de prova, ou seja, é convencional em Mecânica de Enrocamentos a utilização de relações de até $1 / 4$ do diâmetro e, neste caso, sabendo que o diâmetro do corpo de prova seria de $660 \mathrm{~mm}$, limitou-se à utilização de partículas de até $135 \mathrm{~mm}$.

$\mathrm{O}$ resultado da curva granulométrica protótipo, paralela a de campo, é apresentado na Figura 14. Observa-se que durante a mistura das frações granulométricas não foram adicionados finos passantes na peneira $0.075 \mathrm{~mm}$. Esse material foi adicionado posteriormente, com valores entre $5 \%$ e $20 \%$. Durante o procedimento de densificação não foram verificadas visualmente quebras de partículas, possivelmente em decorrência da redução na frequência de vibração. 
Tabela 2 - Composição mineralógica de litologia pobre.

\begin{tabular}{c|c|c}
\hline Mineral & Porcentagem & Dimensões \\
\hline Vidro & $45 \%$ & - \\
\hline Plagioclásio & $25 \%$ & $0.2 \mathrm{a} 0.4 \mathrm{~mm}$ \\
\hline Clinopiroxênio & $20 \%$ & $0.3 \mathrm{a} 0.5 \mathrm{~mm}$ \\
\hline Ortoclásio & $4 \%$ & $\approx 0.20 \mathrm{~mm}$ \\
\hline Opacos & $5 \%$ & $0.1 \mathrm{a} 0.5 \mathrm{~mm}$ \\
\hline Quartzo & $<1 \%$ & - \\
\hline
\end{tabular}

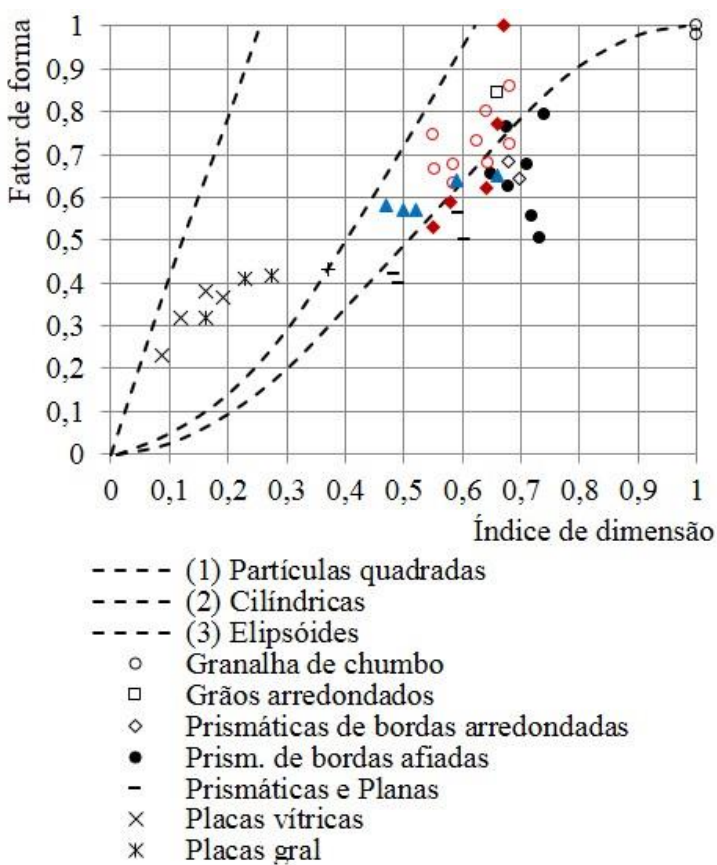

Figura 14 - Curva granulométrica protótipo do enrocamento estudado.

O resultado da curva granulométrica protótipo, paralela a de campo, é apresentado na Figura 14. Observa-se que durante a mistura das frações granulométricas não foram adicionados finos passantes na peneira $0.075 \mathrm{~mm}$. Esse material foi adicionado posteriormente, com valores entre $5 \%$ e $20 \%$. Durante o procedimento de densificação não foram verificadas visualmente quebras de partículas, possivelmente em decorrência da redução na frequência de vibração.

Desta forma, os ensaios foram realizados com reutilização de material, adicionando-se a curva protótipo uma nova porcentagem de finos e procedendo-se novamente com a densificação do corpo de prova.

$\mathrm{Na}$ Figura 15 é possível verificar os gráficos das composições granulométricas utilizadas nos ensaios de densificação. Observa-se na legenda o protótipo lançado para representação dos enrocamentos da UHE Machadinho, neste caso, sem os finos. As demais linhas representam as composições com $5 \%, 10 \%, 15 \%$ e $20 \%$ de finos.

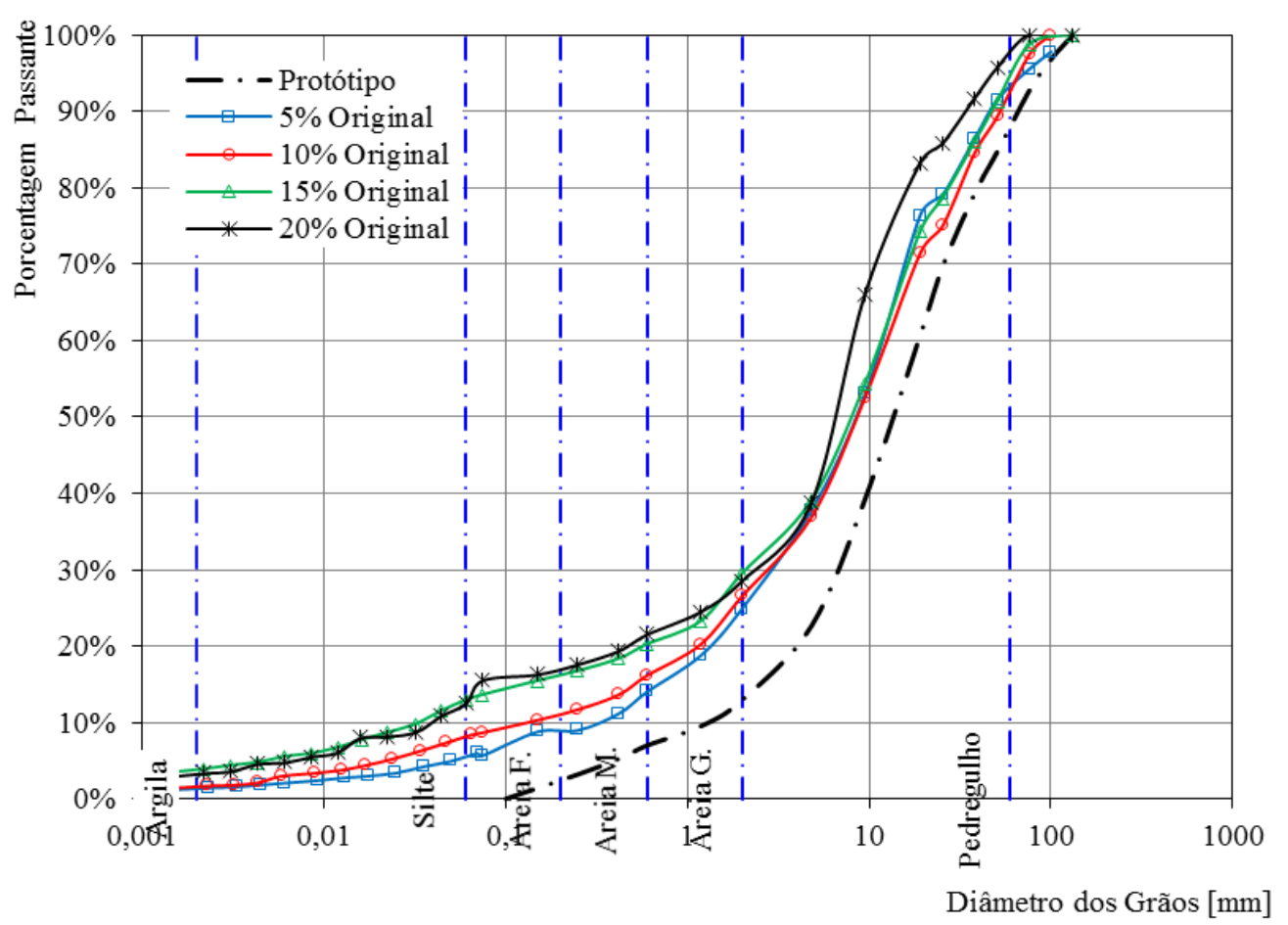

Figura 15 - Curvas granulométricas dos enrocamentos estudados. 
Duas conclusões fundamentais podem ser retiradas deste conjunto de gráficos: A primeira refere-se ao comportamento das curvas frente à adição de finos, em que se pode observar que a curva protótipo encontra-se mais à direta do gráfico, sendo gradualmente deslocada à esquerda em função da adição dos mesmos.

Observa-se também a formação de um ponto de inflexão nas curvas granulométricas próximo ao diâmetro $0.075 \mathrm{~mm}$, atribuiu-se este fato ao procedimento adotado na obtenção de finos, pois as partículas basicamente foram moídas até se tornarem passantes na referida peneira, e devido a limitação executiva, não foi dada a continuidade gradual dessa redução granulométrica.

Devido às dimensões das partículas dos enrocamentos, foram verificados alguns comportamentos atípicos nas curvas. Ou seja, a amostragem para análise granulométrica foi de $50 \mathrm{~kg}$ de material em um montante de $1200 \mathrm{~kg}$, e, durante $\mathrm{o}$ procedimento de quarteamento, eventualmente, partículas de grandes dimensões (>76mm) podem não ter sido introduzidas na composição. Em resumo, uma partícula com diâmetro de $135 \mathrm{~mm}$, com aproximados $2 \mathrm{~kg}$, representaria $4 \%$ da porcentagem passante, justificando comportamentos não esperados. A condição ideal seria submeter todo o material ao procedimento de peneiramento, o que inviabilizaria o estudo, sobretudo em decorrência das elevadas porcentagens de finos.

\section{Apresentação e análise da densificação}

Os corpos de prova foram densificados em moldes metálicos tripartidos, o que permitiu, por exemplo, verificar que durante a desmontagem de uma terça parte o material seco se desagregou, enquanto que o enrocamento úmido permaneceu estável (Figura 16).

Isso pode ser atribuído à capilaridade e consequente coesão aparente do material úmido. Devido ao grande entrosamento entre partículas, mesmo o material densificado a seco não se desagregou completamente. Esse efeito foi constatado ainda nos enrocamentos com $10 \%$, $15 \%$ e $20 \%$ de finos. A diferença de coloração foi provocada pela adição de água.

Após a densificação, foram realizadas inspeções visuais no topo da camada para identificar possíveis quebras de partículas.

Verificou-se que essas foram pouco significativas e muito inferiores às constatadas por

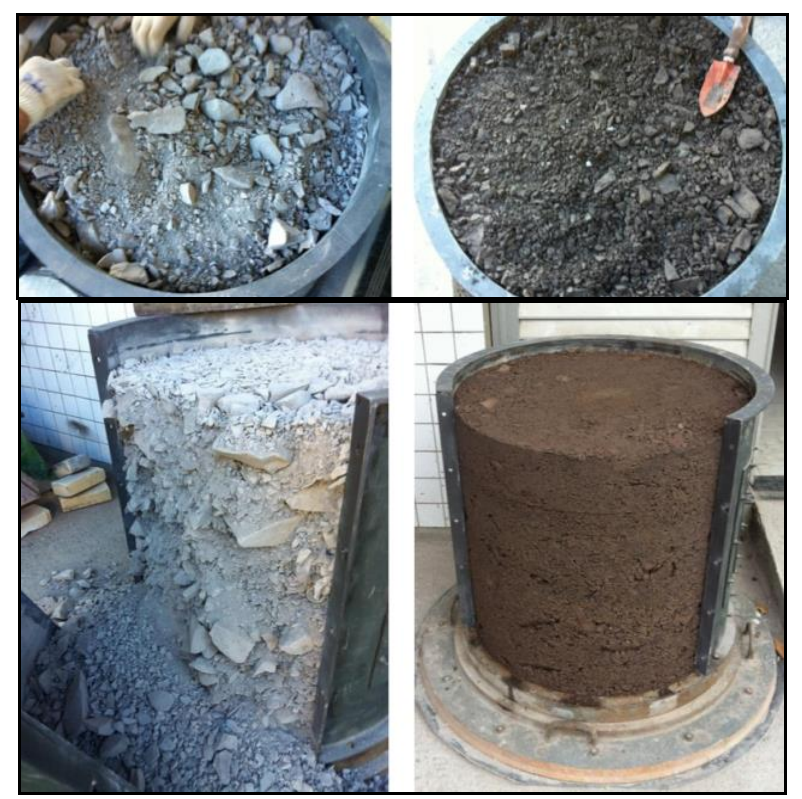

Figura 16 - Material seco e úmido antes e após a densificação.

Pacheco (2005) e Meirelles (2008), possivelmente devido as menores frequências de vibração e a maior porcentagem de finos utilizada nesta pesquisa. Não foram notadas significativas diferenças de quebras entre ensaios secos e úmidos. As espessuras das camadas foram determinadas utilizando-se medidas da diferença de altura entre o topo da camada e a borda superior do molde, em três pontos distanciados $120^{\circ}$, tendose utilizado a média aritmética nos cálculos.

Tabela 03 - Resultados de enrocamentos com 5\% de finos.

\begin{tabular}{c|c|c}
\hline \multirow{2}{*}{ Camada } & \multicolumn{2}{|c}{ Peso Específico Aparente Seco $\left[\mathrm{kN} / \mathrm{m}^{3}\right]$} \\
\cline { 2 - 3 } & $\begin{array}{c}\text { Compactado a } \\
\text { seco }\end{array}$ & Compactado a úmido \\
\hline 1 & 17.89 & 17.47 \\
\hline $1+2$ & 18.33 & 18.39 \\
\hline $1+2+3$ & 18.96 & 18.76 \\
\hline $1+2+3+4$ & 19.38 & 18.89 \\
\hline
\end{tabular}

Na Tabela 3 são apresentados os resultados de pesos específicos aparentes secos $\left(\gamma_{d}\right)$ das camadas densificadas. Verificou-se o aumento do $\gamma_{\mathrm{d}}$ durante o ensaio, que pode ser atribuído ao fato das camadas superiores transmitirem as vibrações para as inferiores resultando em densificação adicional, ou seja, uma sobreposição de efeitos.

Ainda que tenha ocorrido a densificação adicional de camadas inferiores, é notória a tendência à estabilização deste fenômeno para camadas posteriores. Ou seja, minimizam-se variáveis decorrentes destes efeitos em corpos de prova maiores, ou até mesmo no corpo da barragem, garantindo-se homogeneidade ao comportamento do material em profundidade. 


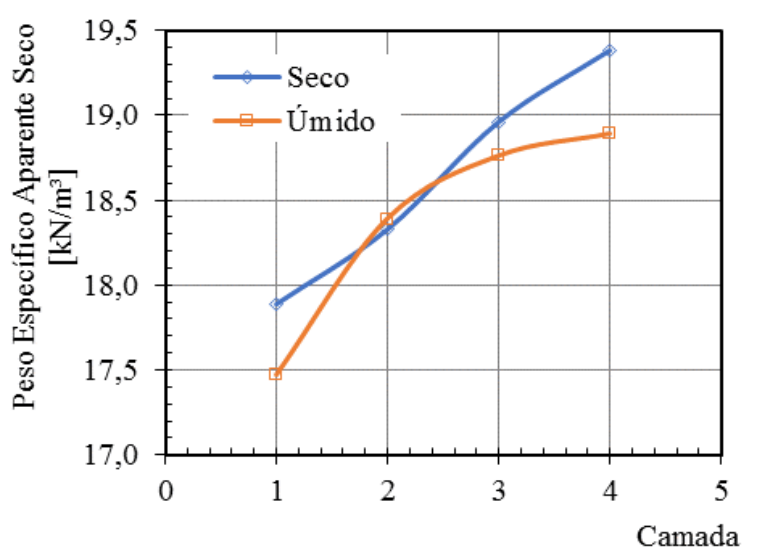

Figura 17 - Resultados de enrocamentos com 5\% de finos.

A Figura 18 e a Tabela 4 demonstram que, diferentemente do ensaio com $5 \%$ de finos, para todas as camadas do enrocamento com $10 \%$ de finos, os valores de $\gamma_{\mathrm{d}}$ do material úmido foram superiores aos do seco. Além disso, as inclinações dos trechos finais das curvas são significativamente menores que $o$ ensaio anterior.

Tabela 4 - Resultados de enrocamentos com $10 \%$ de finos.

\begin{tabular}{c|c|c}
\hline \multirow{2}{*}{ Camada } & \multicolumn{2}{|c}{ Peso Específico Aparente Seco $\left[\mathrm{kN} / \mathrm{m}^{3}\right]$} \\
\cline { 2 - 3 } & $\begin{array}{c}\text { Compactado a } \\
\text { seco }\end{array}$ & Compactado a úmido \\
\hline 1 & 18.68 & 19.5 \\
\hline $1+2$ & 19.73 & 20.09 \\
\hline $1+2+3$ & 20.25 & 20.28 \\
\hline $1+2+3+4$ & 20.13 & 20.34 \\
\hline
\end{tabular}

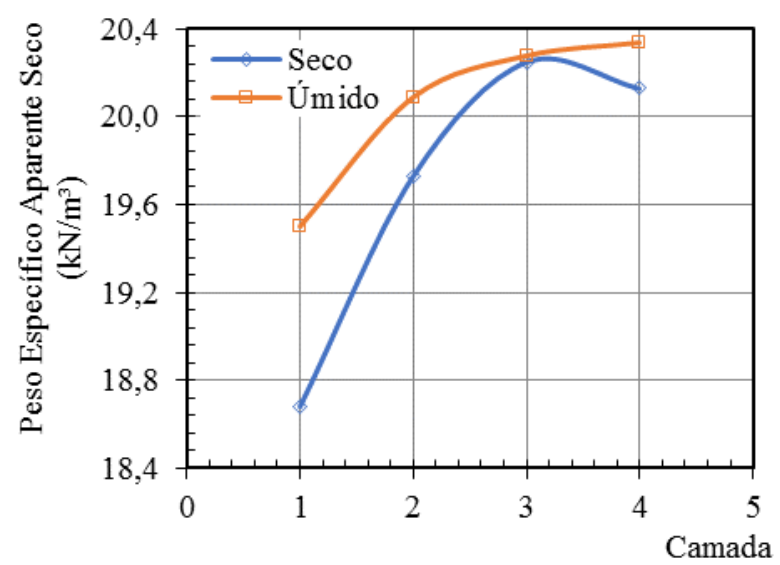

Figura 18 - Resultados de enrocamentos com $10 \%$ de finos.

Pacheco (2005) cita que a utilização de água na densificação de enrocamentos com elevados teores de finos, face ao efeito de capilaridade inicial, pode resultar em diminuição do peso específico aparente do material. Os dados obtidos na Tabela 5 vêm ao encontro de tal afirmação.
Tabela 05 - Resultados de enrocamentos com 15\% de finos.

\begin{tabular}{c|c|c}
\hline \multirow{2}{*}{ Camada } & \multicolumn{2}{|c}{ Peso Específico Aparente Seco $\left[\mathrm{kN} / \mathrm{m}^{3}\right]$} \\
\cline { 2 - 3 } & $\begin{array}{c}\text { Compactado a } \\
\text { seco }\end{array}$ & Compactado a úmido \\
\hline 1 & 18.83 & 18.45 \\
\hline $1+2$ & 20.16 & 19.82 \\
\hline $1+2+3$ & 20.75 & 20.19 \\
\hline $1+2+3+4$ & 20.88 & 20.29 \\
\hline
\end{tabular}

De forma similar aos ensaios com $10 \%$ de finos, as curvas da Figura 19 apresentaram elevada inclinação no trecho inicial e tendência à estabilização no trecho final. Possivelmente, esse fenômeno esteja relacionado com o efeito cumulativo de energias de densificação nas camadas inferiores, ainda que o espraiamento das tensões em materiais de elevado ângulo de atrito interno limite esse efeito para as demais camadas.

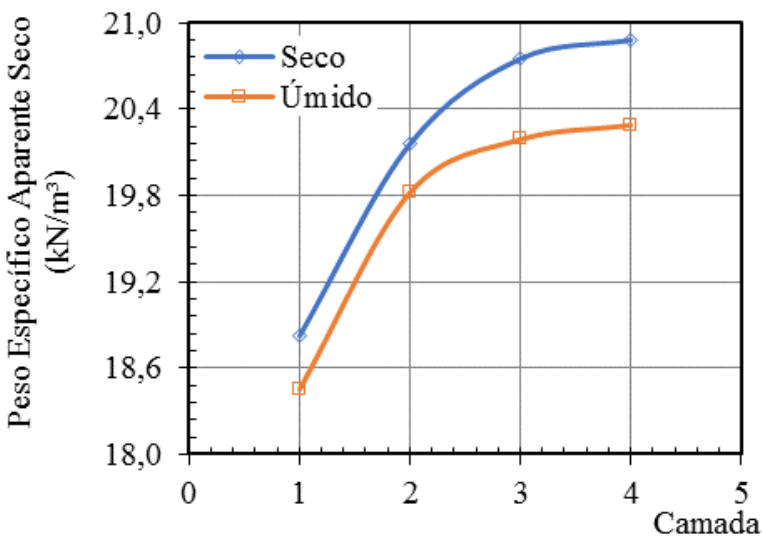

Figura 19 - Resultados de enrocamentos com $15 \%$ de finos.

Os ensaios com $20 \%$ de finos foram realizados, tendo em vista a necessidade de um entendimento maior da influência dos finos em relação à compactação e adição de água em enrocamentos. A Tabela 06 e a Figura 20 apresentam um resumo dos valores de peso específico aparente seco, considerando-se a compactação à seco e à úmido.

Tabela 06 - Resultados de enrocamentos com $20 \%$ de finos.

\begin{tabular}{c|c|c}
\hline \multirow{2}{*}{ Camada } & \multicolumn{2}{|c}{ Peso Específico Aparente Seco $\left[\mathrm{kN} / \mathrm{m}^{3}\right]$} \\
\cline { 2 - 3 } & $\begin{array}{c}\text { Compactado a } \\
\text { seco }\end{array}$ & Compactado a úmido \\
\hline 1 & 19.58 & 18.68 \\
\hline $1+2$ & 20.36 & 19.71 \\
\hline $1+2+3$ & 20.67 & 20.20 \\
\hline $1+2+3+4$ & 20.84 & 20.38 \\
\hline
\end{tabular}

Todos os corpos de prova, com exceção àquele que correspondeu $10 \%$ de finos, apresen- 


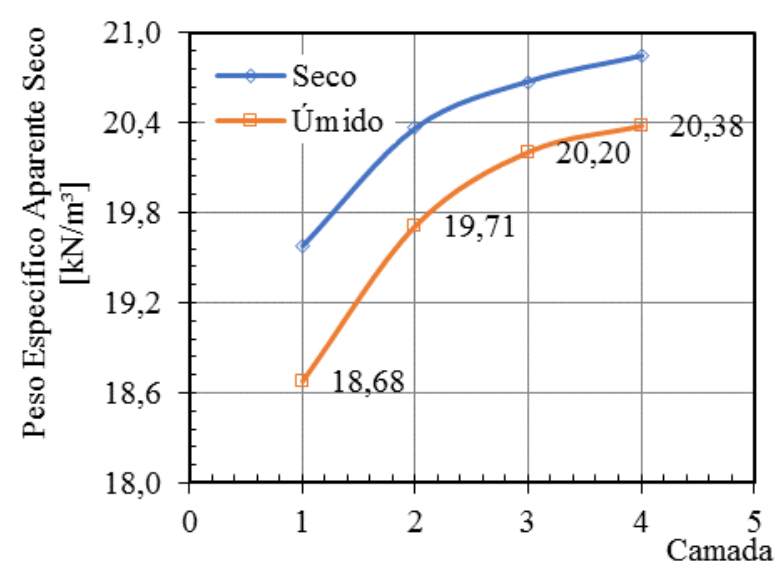

Figura 20 - Resultados de enrocamentos com $20 \%$ de finos.

taram valores de peso específico aparente seco maiores para o material densificado sem adição de água. As Figuras 21 e 22 demonstram graficamente os resultados das compactações à seco e úmido. É possível observar que na compactação à seco existe uma tendência à estabilização do peso específico aparente seco $\left(\gamma_{\mathrm{d}}\right)$ a partir de $15 \%$ de finos. Para a compactação a úmido verifica-se que há o surgimento de um pico de $\gamma_{\mathrm{d}} \operatorname{logo}$ após os $10 \%$ de finos.

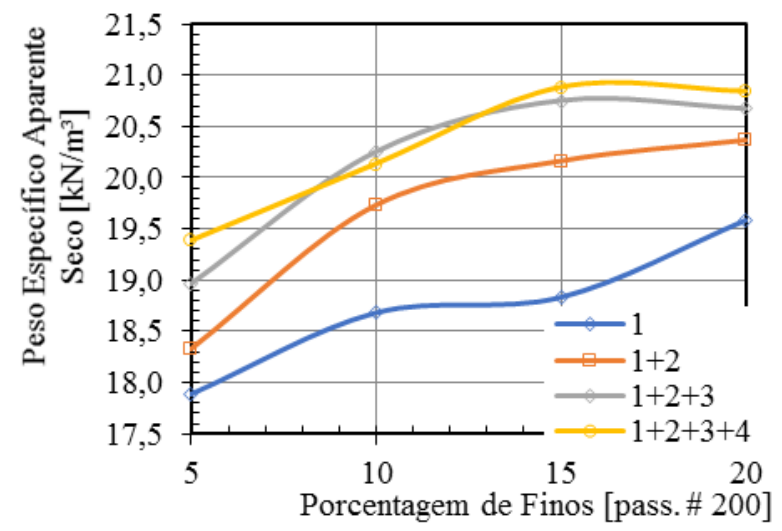

Figura 21 - Variação de $\gamma_{\mathrm{d}}$ com a porcentagem de finos, compactação a seco.

Comparativamente, evidencia-se ainda na Figura 23 que os valores de pesos específicos aparentes secos máximos $\left(\gamma_{\mathrm{d}}\right.$ máx $)$ obtidos na densificação à seco são predominantemente superiores aos valores obtidos para as compactações à úmido.

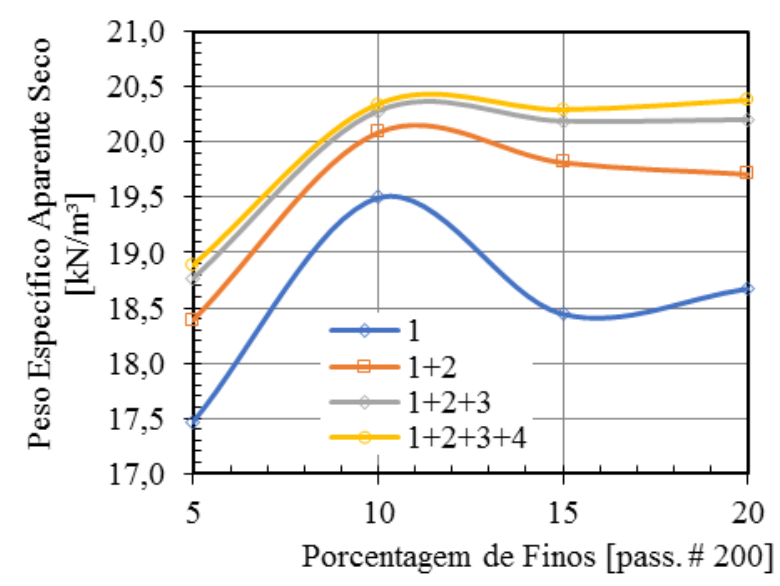

Figura 22 - Variação de $\gamma_{\mathrm{d}}$ com a porcentagem de finos, compactação a úmido.

Estimativa de Pacheco (2005) seria de que em porcentagens mais elevadas de finos, o efeito de capilaridade gerado pela compactação à úmido $(\mathrm{w} \% \approx 6 \%)$ pudesse difícultar a densificação de enrocamentos, e justamente por este motivo se propôs avaliar a influência da adição de finos na compactação e no comportamento mecânico destes materiais.

Obviamente, poderá ocorrer um teor de umidade, a partir do qual a adição de água passará a reduzir novamente o efeito de capilaridade no material, e possivelmente, o fenômeno de colapso da estrutura, como foi evidenciado por Pacheco (2005) nos ensaios de compressão unidimensional.

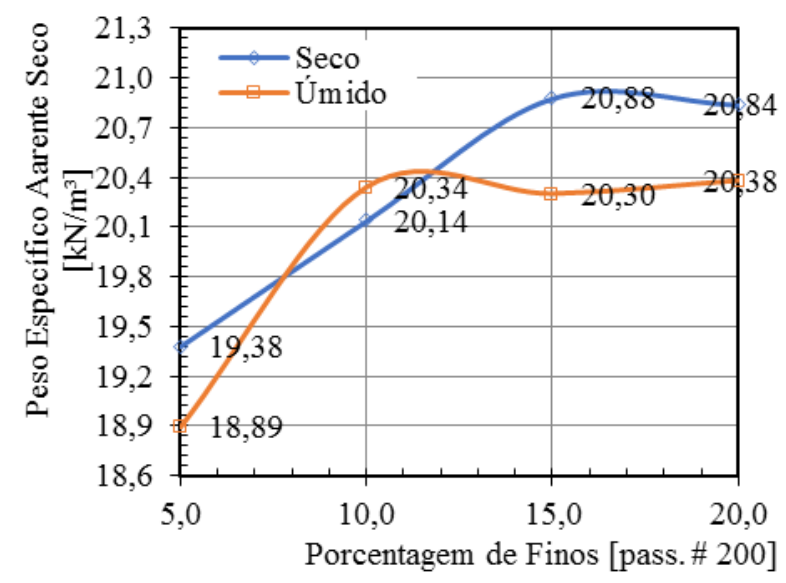

Figura 23 - Valores de $\gamma_{\mathrm{d}}$ com e sem adição de água na densificação.

\section{CONCLUSÕES}

Foi observado que, tanto as britagens primárias, como a secundária, geraram volumes insignificantes de material passante na peneira $0.075 \mathrm{~mm}$. Não obstante, a moagem da fração passante na peneira $4.8 \mathrm{~mm}$ proporcionou porcentagem satisfatória, ainda que o equipamento não tenha sido dimensionado para tal fim. Estudos de grande escala em enrocamentos devem considerar o atraso significativo que a obtenção deste tipo de material tem sobre o cronograma final de uma pesquisa.

Observou-se que quanto mais ciclos de passagens pelo britador, mais cubicas e menos 
alongadas as partículas se tornaram. É importante que se conheçam os formatos dos grãos, pois partículas lamelares são mais quebradiças.

Embora tenha sido evidenciada a formação de um ponto de inflexão nas curvas granulométricas, próximo ao diâmetro $0.075 \mathrm{~mm}$, em decorrência da metodologia de obtenção de finos, os procedimentos executivos para correção deste fenômeno e continuidade gradual da curva inviabilizariam a execução da pesquisa, e teriam aspecto pouco significativo no comportamento amplo do material.

Houve o acréscimo do valor de peso específico aparente seco durante o ensaio de densificação, para camadas inferiores. Isto pode ser atribuído densificação adicional, gerada pela sobreposição de efeitos. Ainda que tenham ocorrido, o espraiamento das tensões evita o prolongamento efetivo e em momento posterior nota-se a tendência à estabilização.

Durante a execução dos ensaios de densi- ficação não foram identificadas quebras significativas de partículas, fenômeno este que possivelmente foi minimizado pela redução na frequência de vibração da placa compactadora, e também pela composição granulométrica bem graduada.

A partir de $15 \%$ de finos, verificou-se que a adição de água passou a prejudicar a compactação das misturas desta pesquisa, fato que não ficou evidente em $10 \%$, e pouco conclusivo para $5 \%$ de finos. Estes dados confirmam a estimativa de Pacheco (2005), que atribui tal fenômeno ao efeito de capilaridade gerado pela densificação à úmido (w\% $\approx 6 \%$ ). Sugere-se que pesquisas futuras verifiquem a influência da variação do teor de umidade e da sucção na densificação de enrocamentos com elevados teores de finos, pois possivelmente haverá um ponto a partir do qual a adição de água passará a reduzir novamente o efeito de capilaridade no material, e a densificação poderá ocorrer, inclusive, por colapso da estrutura.

\section{AGRADECIMENTOS}

Os autores agradecem ao Laboratório central de Microscopia Eletrônica de Varredura da Universidade Federal de Santa Catarina, a Capes, a Tractebel Energia S.A., e ao Engenheiro Rodrigo André Hummes.

\section{REFERÊNCIAS}

ARAEI, A. A.; SOROUSH, A.; RAYHANI, M. Large-Scale Triaxial Testing and Numerical Modeling of Rounded and Angular Rockfill Materials. Scientia Iranica. Sharif University of technology. Arquivo do SID. V.17, N. 3, pp.169-183, 2010.

BREITENBACH, A. J. Rockfill Placement and Compaction Guidelines, Geotechnical Testing Journal, ASTM, Filadelfia, Pensilvânia, v.16, N.1, pp.76-84, 1993.

CHMYZ, L.; VASCONCELLOS, E. M. G.; ARIOLI, E. E.; LICHT, O. A. B. Petrografia e geoquímica de rochas vulcânicas ácidas do tipo palmas aflorantes nas proximidades dos municípios de Palmas e General Carneiro (PR). VII Encontro Internacional de Produção Científica. ISBN 978-858084-055-1. Centro Universitário de Maringá. Ed. Cesumar. PR, Brasil, 2011.

CRUZ, P. T.; MATERÓN, B.; FREITAS, M. Barragens de enrocamento com face de concreto. $2 \mathrm{a}$ ed. Oficina de Textos. ISBN 978-85-7975-155-4. 359p., 2014.

DIVINO, P. L. Comportamento de enrocamentos em barragens - Estudo de caso da barragem de Emborcação. Dissertação de Mestrado, Universidade Federal de Ouro Preto, MG, 226p., 2010.

HUMMES, A. R. Compressibilidade e resistência ao cisalhamento de rejeitos de beneficiamento de carvão mineral em equipamentos de grandes dimensões. Dissertação de Mestrado, Universidade Federal de Santa Catarina, pp. 53-72, 2007.

HUMMES, R. A; MACCARINI, M. Desenvolvimento de um Equipamento Triaxial de Grandes Dimensões para Enrocamentos. ANEEL P\&D Tractebel Energia S.A. 6p., 2009.

LAMBE, T. W.; WHITMAN, R. V. Soil Mechanics. Massachusetts Institute of Technology, John Wiley \& Sons, Nova York, pp. 1-553, 1969.
MACCARINI, M.; ESPÍNDOLA, M. S.; HUMMES, R. A.; GÓMEZ, L. A.; DAL MORO, A. J.; ASSINI JR., E.; OLIVEIRA, A. F. H. L.; MENDES, E.; SILVERIA, E.; CAMPOS, L.; MAESTRI, M. A. P.; RODRIGUES JR. N.; ALMEIDA. P. I. O.; CONTESI, R. J.; MULLER, V. S. Influência da adição de água durante a compactação e do teor de finos no comportamento mecânico de enrocamentos em equipamento triaxial de grandes dimensões. Projeto P\&D 0403-0022/2011. Tractebel Energia S.A. e Universidade Federal de Santa Catarina. 69p., 2014.

MARSAL, R. J. Mechanical Properties of Rockfill. In: Embankment Dam Engineering, R. C. Hirschfel and S. J. Poulos, eds., John Wiley \& Sons, Nova York, pp.109-200, 1973.

MARSAL, R. J.; ROSA, F.; Mechanical properties of rockfill soil mixtures. In: 12th. Congress on Large Dams. 1976, México, v.1, 1976.

MEIRELLES, M. C. Determinação da resistência ao cisalhamento de enrocamento da UHE Machadinho através de ensaios de cisalhamento direto de grandes dimensões. Dissertação de Mestrado, Universidade Federal de Santa Catarina, 123p., 2008.

PACHECO, D. Compressão unidimensional em enrocamento de riodacito e basalto: desenvolvimento do equipamento e realização de ensaios. Dissertação de Mestrado, Departamento de Engenharia Civil, Universidade Federal de Santa Catarina, 2005.

STRECKEISEN, A. L. Classification and nomenclature of igneous rocks. Final report of an inquiry. Abhandlungen aus dem Mathematischen Seminar der Universität Hamburg, 107, pp.144-240, 1967. 
TERZAGHI, K. Discussion on settlement of Salt Springs and Lower Bear River concrete face dams. Transactions of the American Society of Civil Engineers, v.125, p.II, pp.139-148, 1960.

VEIGA PINTO, A. Previsão do Comportamento Estructural de Barragens de Enrocamento, Tese de doutorado, Laboratório Nacional de Engenharia Civil, Lisboa, 1983.
YAMAGUCHI, Y; SATOH, H.; HAYASHI, N.; YOSHINAGA, H. Strength Evaluation of Rockfill Materials Considering Confining Pressure Dependency. In: The 1st International Symposium on Rockfill Dams, 2009

Submetido em 28 de outubro de 2015 Aceito em 04 de maio de 2017 